\title{
PNE (PLANO NACIONAL DE EDUCAÇÃO) 2014 - 2024: A GESTÃO DEMOCRÁTICA NA EDUCAÇÃO SE FAZ PRESENTE?
}

\author{
J. L. M. CARVALHO \\ Instituto Federal de Educação, Ciência e Tecnologia do Piauí \\ jeferson@ifpi.edu.br
}

Artigo submetido em agosto/2015 e aceito em dezembro/2015

DOI: $10.15628 /$ holos.2015.3355

\section{RESUMO}

No ano de 2014, entrou em vigor o novo Plano Nacional de Educação no Brasil (Lei 13.005/2014) que, dentre diversos pontos resultantes de um amplo debate com vários segmentos da sociedade civil organizada, propõe vinte grandes metas que deverão ser realizadas até o ano de 2024. Dentre essas metas destaca-se a da Gestão Democrática da Educação (Meta 19). Objetiva-se neste trabalho debater sobre a conceituação de gestão educacional e gestão democrática, como alicerces para a construção do entendimento dessa meta, constatando que não há um juízo comum sobre a temática e que muitas dificuldades persistem para a sua consecução em tão pouco tempo (dois anos a partir da entrada em vigor da referida Lei).

PALAVRAS-CHAVE: PNE, Gestão Educacional, Gestão democrática na educação.

\section{PNE (NATIONAL PLAN FOR EDUCATION) 2014 - 2024: IS DEMOCRATIC MANAGEMENT IN EDUCATION A REALLITY?}

\begin{abstract}
In the year of 2014 the new National Plan for Education in Brazil came into force (Law 13.005/2014), that among several points resulting of an extensive debate with many sectors of organized civil society, proposes twenty important goals which shall be concluded until the year of 2024. Among these goals the Democratic Management in Education stands out for its relevance. This article aims
\end{abstract}

to discuss the conceptualization of educational management and democratic management, as foundations to the construction of the understanding of this goal, confirming that there is no common sense about the theme and that several difficulties persist for the achievement in a short time (two years since the entry into force of the referred Law)

KEYWORDS: PNE, Educational Management, Democratic management in education 


\section{INTRODUÇÃO}

O Brasil ainda não conseguiu superar suas deficiências em relação à temática proposta, embora venham ocorrendo avanços desde a década de 1930 com a publicação do "Manifesto dos Pioneiros da Educação Nova", em 1932. Nesse período a educação brasileira vivenciou uma bipolarização no ensino com a passagem de uma oligarquia agrária para um processo de urbanização e industrialização.

Ao longo do século passado até o momento atual (segunda década do século XXI), nosso país oscilou entre momentos de regimes autoritários, como a Era Vargas de 1930 a 1945, com a culminância do Estado Novo (1937 a 1945), o Regime Civil-Militar de 1964 a 1985, intercalados por alguns momentos ditos "democráticos" ou de redemocratização. Acompanhando esses momentos históricos nossa educação refletia e reflete a vontade desses períodos. Isso fica implícito nas legislações (Reformas, Leis e Decretos) que procuraram normatizar e regulamentar a educação em nosso país. Podemos citar alguns exemplos dessas legislações como, as Reformas Benjamim Constant (1890), Epitácio Pessoa (1901), Rivadávia Correia (1911), Carlos Maximiliano (1915), Rocha Vaz (1925), Francisco Campos (1931) e Gustavo Capanema (1942), as Leis Orgânicas de 1942, 1943 e 1946, a LDB 4.024/61, a Lei no 5.692/71 (Reforma Universitária), Constituição Federal de 1988, e a LDB 9.394/96. Por último, os Planos Nacionais de Educação: Lei no 10.172/2001 (PNE 2001-2010) e Lei 13.005/2014 (PNE 2014-2024).

O novo Plano Nacional da Educação, Lei 13.005, de 25 de julho de 2014 (PNE 2014-2024), surge com a expectativa de, se não corrigir, pelo menos amenizar diversos problemas na educação brasileira. Nesse plano, que foi muito debatido em diversas instâncias, apresentam-se 20 metas para a educação. Dentre elas esse trabalho abordará a "meta 19", que apresenta uma temática muito importante, a Gestão Democrática na Educação.

Serão analisados os conceitos predominantes que envolvem a temática, como Gestão Educacional; Gestão Democrática e Gestão Democrática na Educação. Por fim, será analisado também como esses conceitos se fizeram e se fazem presentes em diversos textos legais, como a Constituição Federal de 1988 (CF/88) e a Lei de Diretrizes e Bases da Educação Brasileira de 1996 (LDBN/96) e o no novo PNE (2014-2014).

\section{GESTÃO EDUCACIONAL}

Antes de se definir "Gestão Educacional" ou "Gestão na Educação", ou ainda "Gestão Escolar", salienta-se que normalmente os estudos nessa área apontam para a "Direção" das escolas, ou seja, a figura do "Diretor", porém cabe lembrar que essa forma de gestão pode ser e é mais ampla, pois a mesma faz-se presente nos diferentes níveis ou esferas de poder. Assim podese falar em gestão educacional nos Municípios, nos Estados, no Distrito Federal e na União, que por intermédio de suas respectivas descentralizações, regulamentações e financiamentos interferem na forma de gerir as escolas, nos colégios e nas universidades.

Pesquisa realizada por Souza (2009) destaca três períodos no campo da gestão educacional no Brasil: 10 - Escola Clássica (década de 1930 até a década de 1970) em que a gestão da educação era vista como uma especialização da Teoria Geral da Administração; 2o - Escola Crítica (décadas de 1970 e 1980); e 3o - "Estudos Atuais", no qual a gestão escolar é vista como um processo político-pedagógico e aborda temas como "democratização da gestão escolar" (SOUZA, 2009). 
Souza (2009, p. 83) também esclarece que a "administração escolar", termo empregado na Escola Clássica, passa a ser empregado como "gestão escolar" na atualidade, quando há um destaque para a "face política da gestão escolar como prioridade".

Qual seria o perfil adequado de um gestor que contribua com a gestão democrática? Kaufmann (2014, p. 39), responde a esse questionamento ao afirmar que "As constantes mudanças que vêm ocorrendo no mundo de hoje exigem do gestor um perfil mais aberto a novas ideias, voltado para a participação de todos." O autor ainda alerta que "Para isso, uma das características fundamentais para o processo participativo é o que se refere à questão da liderança". E continua destacando que "O gestor deve ser um líder, atento às questões administrativas, pedagógicas e de relacionamento interpessoal." (Kaufmann, 2014, p. 39). E em relação à gestão educacional, como pode ser definida e quais as características de seu gestor? Luck apresenta a seguinte definição:

Gestão educacional corresponde ao processo de gerir a dinâmica do sistema de ensino como um todo e de coordenação das escolas em específico, afinando com as diretrizes e políticas educacionais públicas, para a implementação das políticas educacionais e projetos pedagógicos das escolas, compromissando com os princípios da democracia e com os métodos que organizem e criem condições para um ambiente educacional autônomo (soluções próprias, no âmbito de suas competências) de participação e compartilhamento (tomada conjunta de decisões e efetivação de resultados), autocontrole (acompanhamento e avaliação como retorno de informações) e transparências (demonstração pública de seus processos e resultados). (LUCK, 2011, p. 35-36).

Diante de uma definição tão ampla como a proposta por Luck (2011), sobre gestão educacional surgem novos questionamentos: os atuais gestores educacionais ou escolares estão aptos a exercer essa função? Possuem esse perfil? Souza em sua pesquisa em 2009 revela que,

Os estudos ao longo do século XX no campo da gestão educacional/escolar no Brasil compreendem que o dirigente, especialmente o da escola, é um educador que tem a tarefa de coordenar o esforço coletivo desenvolvido na instituição, pois a gestão é, antes de tudo, a coordenação deste trabalho com vistas aos objetivos educacionais. (SOUZA, 2009, p. 87)

Esse gestor deverá estar alinhado com as características técnicas do cargo, mas também com as características do novo processo de construção de um sistema nacional de educação que estimula uma gestão mais participativa e coletiva, ou seja, deverá saber lidar com a presença de grupos ou conselhos como membros atuantes na gestão. Esse aspecto é reforçado por Schumpeter (1961, p. 300) quando afirma que ele "Governa não apenas sujeito às características da situação nacional, mas sujeito também à necessidade de agir em conjunto com certas pessoas, de se acomodar com outras, de neutralizar algumas e de submeter o resto."

A gestão escolar atual ainda enfrenta o dilema de conviver com a presença de "diretores eleitos", que praticam uma gestão com organismos coletivos, na busca pela autonomia e tenta definir os limites entre direção (focada na pessoa) e a gestão (focado no coletivo) e, os "diretores indicados" que mantêm o "controle centralizado no processo de gestão escolar" o que por sua vez confunde-se com a "figura pessoal do dirigente" (SOUZA, 2009). 


\title{
3 GESTÃO DEMOCRÁTICA NA EDUCAÇÃO
}

A gestão democrática no país é um processo que vem sofrendo mudanças ao longo dos anos, fazendo parte da luta dos educadores. Porém aqui ressalta-se que essa gestão democrática está restrita à educação pública, pois nas instituições escolares privadas com fins lucrativos sua aplicação é totalmente facultativa, o que na prática não se efetiva. Mais do que uma forma de gestão ela é a essência para a consolidação de sonhos e de planos, como pode-se refletir abaixo:

Entendemos que a gestão democrática na educação é parte do projeto de construção da democratização da sociedade brasileira e não simplesmente uma mudança na forma de gestão, que passaria da tecnocrática, vinculada aos preceitos do Fordismo ou atualmente do Toyotismo, para a democrática. (PERONI e FLORES, 2014, p. 186).

Porém, existem diversas dificuldades na concretização da Gestão democrática apontadas por Kaufmann, (2014), que são a falta de comprometimento de alguns gestores; profissionais não enquadrados no perfil do professor; falta de harmonia entre professor e gestor; mudança de gestores com a consequente descontinuidade de processos. Esse mesmo entendimento é apontado por Santos e Nascimento (2014).

Por sua vez, Souza (2009, p. 84) afirma que "A Gestão Democrática é tema muito presente em discussões na educação, desde a escola básica até o ensino superior, margeando especialmente os campos da política e da legislação educacional."

Ressalta-se que, apesar de falar-se em gestão democrática na educação ou na escola, essa não pode ficar restrita aos gestores, deve envolver toda a comunidade escolar, como é evidenciado a seguir,

\begin{abstract}
Entende-se que, se o objetivo é a gestão democrática, não se pode pensar que somente nas questões pedagógicas deve-se ter participação da comunidade escolar. Há de se ter participação da comunidade também nas questões administrativas, inclusive no tocante a como e porque aplicar as verbas em certas aquisições para escola. (PAIXÃO E GUIMARÃES-IOSIF, 2014, p. 2).
\end{abstract}

De acordo com o estudo de Paixão e Guimarães-losif (2014) sobre a percepção da gestão democrática no interior das escolas, a gestão democrática está "atrelada à participação dos sujeitos", mas não se tem clara a definição de comunidade além de não ocorrer a inclusão dos membros dessa comunidade e que há uma centralização na figura do diretor da Escola. Essa afirmação é compartilhada também por Farias e Silva que afirmam: "Trata-se de resgatar o caráter público da administração escolar, para garantir a participação e a autonomia nas escolas públicas. Portanto, deve estender-se igualmente aos aspectos administrativos, financeiros e pedagógicos da escola como um todo." (FARIAS e SILVA, 2014, p. 4).

Outra concordância sobre esse ponto é apresentada por Hora, que afirma,

A gestão democrática na educação inclui, necessariamente, a participação da comunidade no processo educacional, sem o que seria muito mais um arranjo interno dos componentes da escola que atenderiam a interesses que certamente não estariam consentâneos com as expectativas comunitárias. (HORA, 2009, p. 120). 
No estudo de caso realizado por Farias e Silva (2014) são mostradas evidências de "avanços" em relação às "práticas de gestão democrática e participativa" com projetos desenvolvidos a partir da demanda da comunidade e com o aval do Conselho Escolar. "Na gestão escolar democrática permitem-se abrir a escola à participação dos sujeitos escolares, não perdendo de vista as metas educacionais, além de estar em sintonia com as mudanças sociais e a realidade da comunidade escolar." (FARIAS e SILVA, 2014, p. 5).

Em outro estudo, denominado Aprova Brasil (2007), apresentam-se cinco dimensões do aprender, entre elas a Gestão democrática e a participação da comunidade escolar. A gestão democrática é caracterizada nesse estudo como uma instância formal de participação que envolve o conjunto escola-família-comunidade e é vista como fator de contribuição para melhorar a aprendizagem. Esse processo, segundo esse estudo, envolve um diálogo permanente entre conselhos escolares, com participação das famílias e participação dos alunos que deve resultar em uma "decisão coletiva no que diz respeito às práticas pedagógicas" (APROVA BRASIL, 2007).

Deve-se também entender que o processo de democratização na educação brasileira não pode ser confundido como sinônimo de descentralização, que a municipalização do ensino com uma maior participação das comunidades não implica necessariamente no alcance da democracia. “É consenso que a efetivação da gestão democrática nos espaços públicos escolares não é um processo fácil de ser realizado por envolver diferentes pessoas, com diferentes olhares e valores, e por isso mesmo sujeito a tensões e contradições." (FARIAS e SILVA, 2014, p. 6).

\section{A GESTÃO DEMOCRÁTICA NO NOVO PNE}

A temática gestão democrática na educação é abordada pela Constituição Federal (1988), onde o texto legal traz o seguinte em seu Art. 206: "O ensino será ministrado com base nos seguintes princípios: [...] VI - gestão democrática do ensino público, na forma da lei" (BRASIL, 1988). Mesmo sendo posto de forma vaga esse dispositivo abriu caminho para futuras regulamentações.

A LDBN (1996) surge como instrumento legal para promover e regulamentar a gestão democrática na educação brasileira em alguns de seus artigos, como vistos a seguir,

Art. 3o O ensino será ministrado com base nos seguintes princípios:

VIII - gestão democrática do ensino público, na forma desta Lei e da legislação dos sistemas de ensino. (BRASIL, 1996, p. 7);

Art. 14. Os sistemas de ensino definirão as normas da gestão democrática do ensino público na educação básica, de acordo com as suas peculiaridades e conforme os seguintes princípios:

I - participação dos profissionais da educação na elaboração do projeto pedagógico da escola;

II - participação das comunidades escolar e local em conselhos escolares ou equivalentes. [...]

Art. 15. Os sistemas de ensino assegurarão às unidades escolares públicas de educação básica que os integram progressivos graus de autonomia pedagógica e administrativa e de gestão financeira, observadas as normas gerais de direito financeiro público. (BRASIL, 1996, p. 12);

Art. 56. As instituições públicas de educação superior obedecerão ao princípio da gestão democrática, assegurada a existência de órgãos colegiados deliberativos, 
de que participarão os segmentos da comunidade institucional, local e regional. (BRASIL, 1996, p. 25).

Pelo instrumento legal acima, verifica-se que a preocupação com a democracia está presente desde o ensino básico ao ensino superior, mas ainda carente de uma regulamentação de como se processará tal implantação. "No âmbito educacional, a meta era promover mudanças que garantissem a democratização do ensino e a superação dos altos índices de repetência e evasão escolar, bem como o fantasma da falta de vagas nas escolas e de recursos para a educação." (PAIXÃO E GUIMARÃES-IOSIF, 2014, p. 6).

Para suprir a essa falta de regulamentação foi criado um plano nacional para a educação brasileira. Não pretende-se aqui descrever todo o processo de tramitação e implantação desse plano, PNE 2001-2011, bem como do novo plano, PNE 2014-2024, pois este assunto já é bastante abordado em diversas pesquisas e fugiria ao objetivo proposto que é a análise da gestão democrática na educação. Mas essa primeira tentativa não foi suficiente para a resolução dos problemas apresentados na educação, entre os aspectos apontados cita-se o veto ao investimento de $7 \%$ do PIB, que inviabilizou o financiamento dos projetos previstos no PNE. "Com prazo expirado em 2010, este PNE deixou a desejar em diferentes aspectos, tomando-se o princípio constitucional da gestão democrática em educação e a necessidade de uma coordenação nacional de ações para a efetivação de suas metas [...]" (PERONI e FLORES, 2014, p. 182).

Com o término da vigência do PNE anterior, é iniciado um novo debate para a aprovação de um novo PNE que, depois de vários anos e muita discussão entre diversos setores da sociedade civil “É aprovado o Plano Nacional de Educação - PNE, com vigência por 10 (dez) anos, a contar da publicação desta Lei, na forma do Anexo, com vistas ao cumprimento do disposto no art. 214 da Constituição Federal." (BRASIL, 2014, p. 43). Com vista a esclarecer reproduz-se aqui o que estabelece a CF/88 em seu artigo 214:

Art. 214. A lei estabelecerá o plano nacional de educação, de duração decenal, com o objetivo de articular o sistema nacional de educação em regime de colaboração e definir diretrizes, objetivos, metas e estratégias de implementação para assegurar a manutenção e desenvolvimento do ensino em seus diversos níveis, etapas e modalidades por meio de ações integradas dos poderes públicos das diferentes esferas federativas [...] (Redação dada pela Emenda Constitucional no 59, de 2009). (BRASIL, 1988, p. 123).

Uma vez apresentados os conceitos de Educação, Gestão Educacional, Democracia e Gestão Democrática na Educação, têm-se a base teórica para que se possa proceder a uma análise, ponto-a-ponto, sobre a gestão democrática no novo PNE 2014-2024.

No Artigo 20 são definidas as diretrizes do PNE e o inciso VI, trata da "promoção do princípio da gestão democrática da educação pública" (Lei 13.005, 2014), mas sem apresentar qualquer detalhamento ou esclarecimento sobre o que se entende sobre sessa forma de gestão. Apenas no Artigo 9 é elucidado que os entes federados deverão regulamentar a gestão democrática na educação pública, conforme exposto a seguir:

Art. 9o Os Estados, o Distrito Federal e os Municípios deverão aprovar leis específicas para os seus sistemas de ensino, disciplinando a gestão democrática da educação pública nos respectivos âmbitos de atuação, no prazo de 2 (dois) anos contado da publicação desta Lei, adequando, quando for o caso, a legislação local já adotada com essa finalidade. (BRASIL, 2014, p. 46). 
Assim, esses entes federados têm pouco tempo para definir essa legislação sobre um tema tão complexo que há séculos permeia as discussões políticas e filosóficas e que, como já expomos, nem a própria Constituição Federal define democracia.

A gestão democrática irá aparecer novamente no texto legal do PNE, dessa vez como estratégia vinculada à qualidade do ensino, à avaliação de larga escala e aporte financeiro, assumindo a responsabilidade conjunta com a comunidade escolar pela gestão desses recursos.

Meta 7: fomentar a qualidade da educação básica em todas as etapas e modalidades, com melhoria do fluxo escolar e da aprendizagem de modo a atingir as seguintes médias nacionais para o Ideb: [...] 7.16) apoiar técnica e financeiramente a gestão escolar mediante transferência direta de recursos financeiros à escola, garantindo a participação da comunidade escolar no planejamento e na aplicação dos recursos, visando à ampliação da transparência e ao efetivo desenvolvimento da gestão democrática; (BRASIL, 2014, p. 61).

De forma mais direta, a gestão democrática na educação, reaparece na Meta 19 do PNE, reforçando que no prazo de dois anos a mesma deverá ser efetivada. Dicotomicamente, nessa meta, temos a meritocracia e a "consulta pública" lado a lado, o que faz refletir como duas premissas, aparentemente opostas, poderão combinar-se em prol de um objetivo comum. Não se afirma aqui que essas premissas não possam alinhar-se, pois fazem parte do conceito maior que é a democracia, uma vez que esta é bem abrangente, mas cada qual possui em seu âmago formas de constituir-se diferentes. A seguir apresenta-se o escopo dessa meta:

Meta 19: assegurar condições, no prazo de 2 (dois) anos, para a efetivação da gestão democrática da educação, associada a critérios técnicos de mérito e desempenho e à consulta pública à comunidade escolar, no âmbito das escolas públicas, prevendo recursos e apoio técnico da União para tanto. (BRASIL, 2014, p. 83).

Infere-se que essa Meta ilustra o modelo gerencial de administração, com maior força para a meritocracia e, em segundo plano a participação da comunidade escolar, fato esse observado também por Peroni e Flores (2014), quando afirmam que,

Na Meta 19 do novo PNE, a proposta de gestão democrática aparece, dando lugar, em nosso entendimento, a um modelo de gestão gerencial, que aponta de forma genérica a participação da comunidade escolar, ao mesmo tempo em que apresenta princípios gerenciais como critérios técnicos de mérito e desempenho. (PERONI e FLORES, 2014, p. 186).

Com apenas dois anos para a sua realização, prazo esse que pode ser entendido como relativamente curto, pois o tempo já está correndo e a tarefa não é tão fácil quanto parece haja vista que em nossa sociedade até hoje não há um consenso sobre democracia. Além do mais a meritocracia também apresenta suas dificuldades implícitas na sua compreensão, e os estados e municípios, em sua grande parte, não formularam seus planos específicos para a educação ou se o fazem nem sempre é amplamente discutido com a comunidade.

A Meta 19 do PNE é subdividida em estratégias complementares que abordam desde o repasse de recursos da União para os demais entes federados (19.1); estímulos à formação de conselheiros do FUNDEB (19.2); criação de Fóruns Permanentes de Educação nos entes federados (19.3); criação de grêmios estudantis e associações de pais (19.4), conselhos municipais de 
educação (19.5); estímulo a participação da comunidade escolar na formulação dos documentos norteadores e reguladores das escolas (19.6); autonomia pedagógica, administrativa e de gestão financeira nas escolas (19.7); e "desenvolver programas de formação de diretores e gestores escolares" (19.8). (BRASIL, 2014).

A primeira estratégia dessa Meta 19 toca no ponto nevrálgico da educação no Brasil que foi definido como o principal empecilho para a efetivação do PNE anterior, ou seja, o repasse de recursos. Embora não seja aqui que o mesmo vai ser aprofundado, isso caberá à Meta 20, ele se apresenta como um "estímulo" para que os entes federados providenciem suas respectivas legislações, "respeitando a legislação nacional", vinculadas aos critérios de meritocracia e participação comunitária. (BRASIL, 2014). Novamente a questão dinheiro é vinculada ao desempenho (meritocracia) e daí ao gerencialismo em nossa educação.

$\mathrm{Na}$ estratégia seguinte (19.2) há um reforço no entendimento sobre a importância de se estimular a criação de conselhos diversos no âmbito do acompanhamento (controle) das políticas educacionais nos municípios e, inclusive assegurando recursos financeiros para a operacionalização dos mesmos.

Outra vez a fiscalização ou "acompanhamento" das metas do PNE aparece na estratégia 19.3, ao "incentivar" os entes federados a criarem "fóruns Permanentes de Educação" com vistas a coordenar as conferências de educação. (BRASIL, 2014).

Na estratégia 19.4 do PNE, tem-se registrada a preocupação com a participação de pais e alunos de forma mais particularizada e em conjunto aos Conselhos Escolares, através de associação de pais e grêmios estudantis respectivamente, na educação básica sem, contudo, indicar de forma mais clara como será essa participação, outra vez fica-se dependente de regulamentação posterior.

Uma análise dessas estratégias (19.5 e 19.6) revela, de forma geral, que a participação da comunidade escolar assume papel importantíssimo, não só no acompanhamento das práticas de gestão escolar, mas também como órgão construtor dessas práticas. Porém, a responsabilidade criada e repassada a esses sujeitos implica além de sua efetiva participação e envolvimento cotidiano no ambiente escolar, a especialização na formação de conhecimentos especializados em gestão escolar, pois sem saber como funcionam as práticas administrativas da escola, os meandros que envolvem as políticas públicas em educação e o limite de sua autoridade/responsabilidade como membros constitutivos desse processo, corre-se o risco de que se formem apenas grupos desconexos que somente recebem e cumprem as decisões de "cima para baixo".

Uma das formas de participação democrática estimulada no PNE são os Conselhos Escolares. A existência de Conselho Escolar não é garantia para a efetivação de uma Gestão Democrática nas escolas. Uma boa definição é dada por Santos e Nascimento a seguir,

O Conselho Escolar (CE) constitui-se num órgão colegiado que compõe a gestão escolar por meio do qual é possível a participação da comunidade escolar nos processos decisórios da escola. É importante sinalizar que esse Conselho deve reunir representantes de todos os segmentos da escola, de forma que todos sejam representados. (SANTOS e NASCIMENTO, 2014, p. 4).

Esclarecendo um pouco mais sobre os Conselhos Escolares, Santos e Nascimento (2014) os caracterizam conforme exposto no PNL quando afirmam que,

A função do CE está atrelada ao zelo pela manutenção da escola e à participação da gestão administrativa, pedagógica e financeira, coletivamente, contribuindo 
assim com as ações dos dirigentes escolares, em busca de assegurar a qualidade de ensino. Entre as atividades dos conselheiros estão, por exemplo, definir e fiscalizar a aplicação dos recursos destinados à escola e discutir o projeto pedagógico com a direção e os professores. (SANTOS e NASCIMENTO, 2014, p. 5).

Outro ponto a chamar a atenção está na estratégia 19.7 quando a mesma refere-se a "autonomia pedagógica, administrativa e de gestão financeira nos estabelecimentos de ensino." (BRASIL, 2014). Em situações anteriores, como no caso da Proposta de Emenda à Constituição PEC 370/1996, a discussão sobre a autonomia universitária induzia a uma discussão sobre privatização da mesma, talvez por isso essa emenda nunca tenha sido aprovada. (CÂMARA DOS DEPUTADOS, 1997). É preciso estar atendo a definição de autonomia, pois as atuais políticas na educação pública podem carregar um viés para a criação de condições que conduzam a um sistema de quase-mercado na educação pública do país.

Na última estratégia (19.8) da Meta 19, mais uma vez o gerencialismo e a meritocracia se fazem presentes. Com a "formação de diretores e gestores" para as escolas públicas fica subtendida a intenção de um possível "adestramento" desses sujeitos aos ditames de uma administração gerencial nas escolas, isso dependerá da regulamentação a ser definida para os órgãos promotores dessa "capacitação", mas fica evidenciada a meritocracia através da análise de resultados medidos pela aplicação de uma "prova nacional" a esses gestores. Fica então a pergunta: como aplicar princípios democráticos à gestão na educação, como, por exemplo, a eleição de diretores, se os mesmos deverão ser submetidos a um doutrinamento e avaliados mediante uma prova? E a autonomia pregada na estratégia anterior, como fica?

\section{CONCLUSÕES}

Pelo exposto, infere-se a acreditar que a democracia é um sistema que direta ou indiretamente envolve todos os cidadãos no processo decisório. Porém têm-se alertas de estudos que essa realidade não é bem assim, como explica Markoff (2013) ao afirmar que a "Democracia era um sistema que incluía algumas pessoas com plenos direitos, os quais eram negados a outras." (MARKOFF, 2013, p. 23).

Tem-se, dessa forma, uma democracia excludente, por exemplo: menores de 16 anos não podem votar e escolher seus representantes políticos, e como então pode-se falar em democracia nas escolas de uma forma plena incluindo esses mesmos alunos na escolha dos dirigentes onde os mesmos estudam? Como explicar que na escola eles podem praticar a democracia através de grêmios estudantis e/ou Conselhos Escolares, mas que sua cidadania fora dos muros da escola é limitada? Paixão e Guimarães colaboram que essa reflexão quando afirmam que a "Escola e democracia são temas interligados, polissêmicos e contraditórios. Percebe-se que o acesso à escola nem sempre foi considerado um direito de todos, assim como a própria democracia não necessariamente foi pensada para todos." (PAIXÃO E GUIMARÃES-IOSIF, 2014, p. 3).

Mesmo previsto nas leis que regem a educação nacional, muitos municípios ainda não organizaram essa instância de participação democrática. No prazo de dois anos, que já começou a correr, pois o novo PNE já está em vigor, esses municípios terão que lidar com a autonomia/descentralização administrativa, financeira e pedagógica nas escolas, deverão promover a eleição para dirigente escolar, precisarão incentivar e formar o Conselho Escolar. Fará parte de sua pauta de debates temas como a autonomia escolar, participação e transparência. Tudo isso, se bem discutido e regulamentado, deverá criar uma escola democrática, assim definida 
por Paixão e Guimarães: “A escola democrática pressupõe que todos tenham seus anseios minimamente supridos ou acolhidos; que todos sejam considerados sujeitos de direitos, isto é, cidadãos; que todos se sintam parte e que façam parte da escola." (PAIXÃO E GUIMARÃES-IOSIF, 2014, p. 5).

Como lidar com tudo isso pressupondo-se que vive-se em um momento em que o estado do liberalismo econômico se faz presente e que suas ações tendem para um processo gradativo de criação de um "quase-mercado" com vistas à privatização, se não total, mas parcial, da educação? Esse ponto é alertado por Peroni e Flores (2014) que refletem:

Essa opção do Governo Federal, por si só, aponta uma tendência privatista da educação, que fragiliza, em nosso entendimento, os próprios princípios constitucionais de gratuidade, laicidade e qualidade, comprometendo, ainda, o compromisso com a gestão democrática na educação pública. (PERONI e FLORES, 2014, p. 185).

Hoje está em voga a busca por uma simetria entre os Planos Nacional, Estaduais e Municipais de Educação, levando a construção de um sistema nacional de educação, como afirma Saviani,

De modo similar, também na educação, constituído o sistema nacional, as normas se estendem a todos os estados e municípios, o que os dispensaria de reiterar as normas comuns, bastando estabelecer as normas tendentes a ajustar aquelas regras comuns às particularidades de cada estado ou município. (SAVIANI, 2010, p. 384).

Ou seja, conforme entendimento de Saviani (2010), seguindo-se a elaboração de normas em nível nacional, os estado e municípios apenas se adequariam a essa regulamentação, criando de fato um sistema nacional que como dizem seria realmente "articulado".

O PNE 2014-2024 está aí. Discutiu-se amplamente para a sua formulação, discutir-se-á amplamente para a sua regulamentação, discutir-se-á amplamente para entendê-lo, discutir-se-á amplamente para aplica-lo. Será que em meio a tantas discussões esse prazo de 10 anos será suficiente? Ou veremos repetir a história do PNE anterior e, quando atentarmos, estaremos novamente discutindo o próximo PNE sem termos alcançado o mínimo proposto pelas metas do atual plano.

\section{REFERÊNCIAS}

1. Aprova Brasil: o direito de aprender: boas práticas em escolas públicas avaliadas pela Prova Brasil / [parceria entre] Ministério da Educação; Instituto Nacional de Estudos e Pesquisas Educacionais Anísio Teixeira; Fundo das Nações Unidas para a Infância. - 2. ed. - Brasília: Fundo das Nações Unidas para a Infância, 2007.103 p.: il. Disponível em: <http://www.unicef.org/brazil/pt/aprova_final.pdf>. Acesso em: 21 out. 2014.

2. BRASIL. Constituição [de 1988] da República Federativa do Brasil. disponível em: <http://www.planalto.gov.br/ccivil_03/constituicao/ConstituicaoCompilado.htm>. Acesso em 19 out. 2014.

3. BRASIL. Lei no 9.394, de 20 de dezembro de 1996. Estabelece as Diretrizes e Bases da Educação Nacional. Disponível em: http://www2.senado.leg.br/bdsf/bitstream/handle/id/ 
70320/65.pdf?sequence=3>. Acesso em 19 out. 2014.

4. BRASIL. Lei no 13.005, de $\mathbf{2 5}$ de junho de 2014. Aprova o Plano Nacional de Educação (PNE) e dá outras providências. 2. ed. Brasília: Câmara dos Deputados, Edição Câmara, 2015. Disponível em http://bd.camara.gov.br/bd/bitstream/handle/bdcamara/20204/plano_nacional_educacao_ 2014-2024_2ed.pdf?sequence=8>. Acesso em: 19 out. 2015.

5. BOBBIO, Norberto. O futuro da democracia; uma defesa das regras do jogo. Tradução de Marco Aurélio Nogueira. Rio de Janeiro: Paz e Terra, 1986.

6. DICIONÁRIO AURÉLIO. Site [S.I.: s.n.], 2008. Disponível em: <http://www.dicionariodoau relio.com/>. Acesso em: 19 out. 2014.

7. CÂMARA DOS DEPUTADOS. (1997), Substitutivo à Proposta de Emenda à Constituição no 370/96. Da Comissão Especial Encarregada da Apreciação da PEC no 370/96. Relator: Dep. Paulo Bornhausen. Brasília, Câmara dos Deputados, 07 de outubro. (Avulso).

8. FARIAS, M. S. B.; SILVA, K. V. A. Democratizando a gestão: do projeto pedagógico ao conselho escolar. IV Congresso Ibero-Americano de Política e Administração da Educação / VII Congresso Luso Brasileiro de Política e Administração da Educação. Porto, Portugal, 2014. Disponível em: <http://www.anpae.org.br/IBERO_AMERICANO_IV/GT1/GT1_Comunicacao/ MariadaSaleteBarbozadeFarias_GT1_integral.pdf>. Acesso em 21 out. 2014.

9. HORA, D. L. Gestão democrática na escola. 15. ed. São Paulo: Papirus, 2009.

10. KAUFMANN, C. Barreiras de uma gestão democrática: Dificuldades encontradas para que a Democracia se consolide na gestão. Unoesc \& Ciência - ACHS, Joaçaba, v. 5, n. 1, p. 33-42, jan./jun. 2014.

11. LUCK, H. Gestão educacional: uma questão paradigmática. 8. ed. Petrópolis: Vozes, 2011.

12. MARKOFF, J. Democracia: transformações passadas, desafios presentes e perspectivas futuras. Sociologias, Porto Alegre, ano 15, n. 32, jan./abr. 2013, p. 18-50.

13. PAIXÃO, G. A. M.; GUIMARÃES-IOSIF, R. M. A gestão democrática e o desafio de gerir juntos os recursos da escola. IV Congresso Ibero-Americano de Política e Administração da Educação / VII Congresso Luso Brasileiro de Política e Administração da Educação. Porto, Portugal, 2014. Disponível em: <http://www.anpae.org.br/IBERO_AMERICANO_IV/GT1/ GT1_Comunicacao/GleiceAlineMirandadaPaixao_GT1_completo.pdf>. Acesso em: 21 out. 2014.

14. PERONI. V. M. V.; FLORES, M. L. R. Sistema nacional, plano nacional e gestão democrática da educação no Brasil: articulações e tensões. Educação (Porto Alegre, impresso), v. 37, n. 2, p. 180-189, maio-ago. 2014.

15. SANTOS, A. L. F.; NASCIMENTO, J. S. Gestão democrática e os processos indutivos do Plano de Ações Articuladas (par): analisando os municípios de llha de Itamaracá e Itapissuma (PE). IV Congresso Ibero-Americano de Política e Administração da Educação / VII Congresso Luso Brasileiro de Política e Administração da Educação. Porto, Portugal, 2014. Disponível em: <http://www.anpae.org.br/IBERO_AMERICANO_IV/GT1/GT1_Comunicacao/AnaLuciaFe lixdosSantos_GT1_integral.pdf>. Acesso em: 19 out. 2014.

16. SAVIANI, D. Sistema nacional de educação articulado ao plano nacional de educação. Revista Brasileira de Educação v. 15 n. 44 maio/ago. 2010. Disponível em: 
<http://www.scielo.br/pdf/rbedu/v15n44/v15n44a13.pdf.>. Acesso em: 26 out. 2014.

17. Sistema de educação: subsídios para a conferência nacional de Educação. Brasília: MEC/CONAE, 2009. Texto organizado a pedido da assessoria do MEC para servir de subsídio às discussões preparatórias da CONAE. Disponível em $<$ http://conae.mec.gov.br/images/stories/pdf/conae_dermevalsaviani.pdf>. Acesso em: 26 out. 2014.

18. SCHUMPETER, J. Capitalismo, socialismo e democracia. Rio de Janeiro: Fundo de Cultura, 1961.

19. SOUZA, $A \mid$. R. A pesquisa no campo da gestão da educação: algumas reflexões sobre as relações entre produção do conhecimento e a prática da gestão educacional. Revista Retratos da Escola, Brasília, v. 3, n. 4, p. 81-94, jan./jun. 2009. Disponível em: < http://www.esforce.org.br/index.php/semestral/article/view/103/292>. Acesso em: 27 out. 2014. 